\title{
The influence of low blood lead concentrations on the cognitive and physical development of primary school children in Malaysia.
}

\begin{abstract}
This study aimed to determine the relationship between blood lead $(\mathrm{BPb})$ concentrations and cognitive and physical development in school children. A total of 169 urban children and 100 industrial children of Malay ethnicity, in the age range of $61 / 2$ to $81 / 2$ years, were selected. $\mathrm{BPb}$ was determined using GF atomic absorption spectrophotometer. The mean cognitive score (102.55) of the children from the industrial area was significantly higher than that of the urban children (95.09; $\mathrm{P}<.001)$. However, no significant differences were found in the $\mathrm{BPb}$ levels between the 2 groups (industrial, $3.75 \mu \mathrm{g} / \mathrm{dL}$; urban, $3.56 \mu \mathrm{g} / \mathrm{dL}$ ). There was significant inverse correlation between $\mathrm{BPb}$ and cognitive scores for all children $(\mathrm{P}<.05)$. The cognitive scores for all children were influenced by $\mathrm{BPb}$ after adjustments $(\mathrm{P}<.05)$. The urban children had significantly better Weight for Height and Left Arm Circumference values than those from industrial area. There was no significant correlation between $\mathrm{BPb}$ and the anthropometric measurements. In conclusion, low $\mathrm{BPb}$ influenced the cognitive development, whereas physical development was not affected.
\end{abstract}

Keyword: Low blood lead; Cognitive performance; Physical development; Anthropometric measurements. 